\title{
Research on the Mechanical Properties, Fluoride and Monomer Release of a New Experimental Flowable Giomer in Comparison to Three Commercial Flowable Giomers
}

\author{
Mara Elena Rusnac ${ }^{1}$, Doina Prodan ${ }^{2, *}$, Marioara Moldovan ${ }^{2}$ (D), Stanca Cuc ${ }^{2}$, Miuţa Filip ${ }^{2}$ (D), \\ Cristina Prejmerean ${ }^{2}$ and Diana Dudea ${ }^{3}$ D
}

1 Department of Conservative Odontology, Iuliu Hatieganu University of Medicine and Pharmacy, 33 Motilor Street, 400001 Cluj-Napoca, Romania; rusnac.mara@umfcluj.ro

2 Department of Polymer Composites, Babeş-Bolyai University, Raluca Ripan Institute for Research in Chemistry, 30 Fantanele Street, 400294 Cluj-Napoca, Romania; marioara.moldovan@ubbcluj.ro (M.M.); stanca.cuc@ubbcluj.ro (S.C.); miuta.filip@ubbcluj.ro (M.F.); cristina.prejmerean@ubbcluj.ro (C.P.)

3 Department of Prosthetic Dentistry and Dental Materials, Iuliu Hatieganu University of Medicine and Pharmacy, 32 Clinicilor Street, 400006 Cluj-Napoca, Romania; ddudea@umfcluj.ro

* Correspondence: doina.prodan@ubbcluj.ro; Tel.: +40-724-254-336

Citation: Rusnac, M.E.; Prodan, D.; Moldovan, M.; Cuc, S.; Filip, M.; Prejmerean, C.; Dudea, D. Research on the Mechanical Properties,

Fluoride and Monomer Release of a New Experimental Flowable Giomer in Comparison to Three Commercial Flowable Giomers. Appl. Sci. 2021, 11, 8921. https://doi.org/10.3390/ app11198921

Academic Editors: Paola Gandini and Andrea Scribante

Received: 1 September 2021

Accepted: 21 September 2021

Published: 24 September 2021

Publisher's Note: MDPI stays neutral with regard to jurisdictional claims in published maps and institutional affiliations.

Copyright: (c) 2021 by the authors. Licensee MDPI, Basel, Switzerland. This article is an open access article distributed under the terms and conditions of the Creative Commons Attribution (CC BY) license (https:/ / creativecommons.org/licenses/by/ $4.0 /)$.

\begin{abstract}
Giomers are hybrid dental materials with controlled fluoride release properties. The aim of this study was to characterise a new experimental flowable giomer $(G)$ in comparison to three commercial flowable giomers: Beautifil flow Plus X F00 (B-F00), Beautifil flow F02 (B-F02) and Beautifil flow Plus X F03 (B-F03), Shofu, Kyoto, Japan. The studied properties are fluoride ion release, residual monomers release and mechanical properties. The data analysis was performed using the ANOVA test and Tukey test for post hoc comparisons between groups. During the first day of the fluoride releasing measurement, the following classification resulted: B-F02 > B-F03 > B-F00 > G and at the end of the investigation period, at 60 days: B-F02 > B-F03 > G > B-F00. The experimental giomer released a lower percentage of total residual monomers than the commercial giomers. The highest value for the mechanical properties was recorded for the commercial giomers. The experimental giomer registered the lowest values for mechanical properties but higher than the imposed standard limit. There were statistically significant differences between the analyzed materials, in terms of fluoride releasing, residual monomer releasing and mechanical properties.
\end{abstract}

Keywords: dentistry; flowable giomers; fluoride release; residual monomers; mechanical strength

\section{Introduction}

The necessity of restorative materials for different clinical situations was responsible for the development of new versions among which the flowable materials play an important role. Resin based flowable materials are characterized by low viscosity and high elasticity, properties that make them highly recommended for the restoration of complex and difficult areas like the cervical portion of a tooth or the marginal ridges [1,2]. Recently developed flowable materials are reported to have superior mechanical properties and wear resistance, making them applicable in a wide variety of restorative cases, some of them with mechanical properties similar to conventional resin matrix based restoratives [3-5].

Giomers represent a new development in the hybrid material category and consist in a stable glass-ionomer faze, on a glass core resulted from an acid-base reaction between fluoridated glass and poly-carboxylic acid, in the presence of water ("Pre-Reacted Glassionomer filler" or PRG). This material is proven to have anti-plaque effect, reducing the adherence of harmful bacteria to the tooth structure, is adequate for the treatment of hypersensitivity and non-cytotoxic to human teeth [6]. Appling PRG-technology to the filler in resin based composite materials gives them bioactive properties through fluoride 
release and recharge, similar to traditional glass-ionomers, but maintaining in the same time physical and esthetical properties of the composites $[7,8]$.

Flowable materials in the form of giomers have very specific clinical indications in the field of restorative dentistry, because of their flexibility and quality of adhesion to enamel and dentine [9].

Flowable giomers have a several applications in the practical field, in function with the filler percentage. The higher filler percentage and strong mechanical properties of B-F00, makes it able to withstand the restoration of occlusal anatomy, class V restorations and marginal ridges, where the highest forces are applied. A lower filler percentage and lower mechanical properties, but higher fluidity and wettability make B-F03 indicated for class $\mathrm{V}$ restorations, small fillings or as cavity liner, where the ability of a filling material to flow and fill all details are most important [10]. The B-F02 material with lower mechanical properties and lower filler percentage, make it suitable for small or superficial restorations (class I to III and class V) and also as cavity liner [10].

To the best of our knowledge, very few references are available in literature regarding these materials [11-13]. Giomers were characterized regarding optical properties, translucency and masking capacity [12], water sorption and solubility [11,13].

Bioactive materials bring benefits regarding carious protection trough fluoride release. The capacity to release a protective amount of fluoride is dependent on the hydric degradation of the incorporated bioactive glass. However, the interaction with oral fluids has consequences on the mechanical properties of a material and on the surface roughness [14]. Similar to glass-ionomers, giomers act like fluoride reservoirs, with the initial high concentration release phase lasting $24-48 \mathrm{~h}$. This value will decrease over time, reaching a stable point in 3 to 5 weeks after application $[7,15]$. Clinically, the most important aspect regarding fluoride release is the limitation of secondary caries, the main cause for direct restoration early replacement [16-20]. The PRG-filler (pre-reacted glass filler) technology proved effective against bacteria responsible for caries apparition, including Streptoccocus Mutans $[17,21,22]$.

The fluoride recharging capacity form the oral environment of giomer materials can benefit from the application of gels, varnishes, usage of fluoridated mouth wash or tooth paste. [20-23]. Over time, the quantity of fluoride released into the oral environment will decrease, resulting in porous defects in the resin matrix [20,23]. The most effective method for enamel remineralization and incipient caries remineralisation, at the present time, is through the local application of fluoride [24].

Any cured composite, including the giomer variation, has some degree of unreacted monomers trapped inside the matrix. The degree of conversion of a composite based material is important when determining its biocompatibility. Depending on the monomers in the composition of the material, the elution of residual monomers is different. The factors that influence the conversion degree are the photo-polymerization conditions and the quantity of photo-initiator. All interaction with oral fluids and specific filler percentage inside the resin matrix will have an impact on the mechanical properties of bioactive restorative materials [25].

The objective of the present study is to create a detailed comparison between an experimental flowable giomer produced by the chemistry laboratory at Babeş Bolyai University in Cluj-Napoca and three commercial flowable giomers from Shofu Inc. Kyoto, Japan, regarding fluoride release, residual monomers, and mechanical properties. All of the materials included in the study have the same polymeric matrix: Bis-GMA/TEGDMA (2,2-Bis[p-(2hydroxy-3-methacryloyloxypropoxy)-phenyl]-propane/triethylene glycol dimethacrylate) and different fillers in different percentages.

The null hypothesis is that no statistically significant difference can be found between the analyzed materials, regarding fluoride release, residual monomer and mechanical properties. 


\section{Materials and Methods}

\subsection{Studied Materials}

For this study we chose the following commercial materials: Beautifil Flow F02, Beautifil Flow Plus X F00, Beautifil Flow X F03 (from manufacturers' instructions-Shofu Inc. Kyoto, Dental Corporation, Japan) and the experimental giomer obtained at Babeș-Bolyai University, Raluca Ripan Institute for Research in Chemistry, (Cluj-Napoca, Romania). Table 1 contains the composition of the materials investigated.

Table 1. Commercial Giomer and experimental flowable giomer composition.

\begin{tabular}{|c|c|c|c|}
\hline Name & Code & Composition & Consistency \\
\hline Beautifil flow Plus X F00 & B-F00 & $\begin{array}{l}\text { 10-20\% Bis-GMA, TEGDMA, Bis-MPEPP, } \\
\text { 50-60\% S-PRG filler based on } \\
\text { fluoroboroaluminosilicate glass, polymerization } \\
\text { initiator, pigments and others }\end{array}$ & Minimal flow \\
\hline Beautifil flow F02 & B-F02 & $\begin{array}{l}20-30 \% \text { Bis-GMA, TEGDMA, } 40-50 \% \text { S-PRG } \\
\text { filler based on fluoroboroaluminosilicate glass, } \\
\text { polymerization initiator, pigments and others }\end{array}$ & Low flow \\
\hline Beautifil flow Plus X F03 & B-F03 & $\begin{array}{l}\text { 10-20\% Bis-GMA, TEGDMA, Bis-MPEPP, } \\
\text { 50-60\% S-PRG filler based on } \\
\text { fluoroboroaluminosilicate glass, polymerization } \\
\text { initiator, pigments and others }\end{array}$ & Low flow \\
\hline Experimental giomer * & G & $\begin{array}{l}40 \mathrm{w} \% \text { Bis-GMA, TEGDMA (3:1), } 60 \mathrm{w} \% \text { filler } \\
\text { (SPRG, Exp-Glass, Dentalglass, FHAP) }\end{array}$ & Low flow \\
\hline
\end{tabular}

* Bis-GMA, SPRG, Exp-Glass and FHAP were obtained at the Babes-Bolyai University, Raluca Ripan Institute for Research in Chemistry, (Cluj-Napoca, Romania). TEGDMA, CQ, DMAEM was purchased from Aldrich. Dentalglass $(0.7 \mu \mathrm{m})$ was provided by Ferro GmbH, Frankfurt am Main-Germany.

For of the experimental giomer, monomer-Bis-GMA analog (93\% 2,2-Bis [p-(2-hydroxy3-methacryloyloxypropoxy)-phenyl]-propane monomer and 7\% dimer, obtained at BabeșBolyai University, Raluca Ripan Institute of Chemistry Research (Cluj-Napoca, Romania) was used as base in the polymer matrix [14]. As a diluting monomer triethylene glycol dimethacrylate (TEGDMA) was used; the photochemical initiation system had the following components: $0.5 \%$ camphorquinone (CQ) as the photosensitizer and $1 \%$ dimethylaminoethyl-methacrylate (DMAEM) as the accelerator; all from Sigma Aldrich Chemical Co. (Taufkirchen, Germany). Experimental glass powder (Exp-Glass), fluorohydroxyapatite (FHAP) and pre-reacted glass (SPRG) were also synthesized in the UBBICCRR laboratory. Exp-Glass was silanized with 3-methacrylyloxypropyl-1-trimethoxysilane (A-174 silane) from Aldrich. Methods for obtaining and the characterization of the inorganic filler components are presented in literature $[25,26]$.

\subsection{Characteristics Investigated for the Selected Materials}

\subsubsection{Fluoride Release}

For this experiment, a number of 5 samples (1 $\mathrm{mm}$ thickness, $15 \mathrm{~mm}$ in diameter) were prepared from each material. The light curing was performed for $20 \mathrm{~s}$ with a LED.E (GuilinWoodpecker Medical Instruments Co., Guangxi, China), having the wavelength in the range of $470 \mathrm{~nm}$ and the intensity of $950 \mathrm{~mW} \mathrm{~cm}$. The samples were placed in $45 \mathrm{~mL}$ of distilled water and $5 \mathrm{~mL}$ of TISAB III buffer (total ionic strength adjustment buffer, concentrated solution, HI 4010-06, Hanna Instruments, Woonsocket, RI, USA) at $37^{\circ} \mathrm{C}$. The specific measurements were performed daily for the first 7 days of the experiment, and then on the 14th, 21st, 30th and 60th days. After each determination, each sample was placed in the same polyethylene container and the temperature was kept constant at $37^{\circ} \mathrm{C}$ with a thermostatic bath [26].

The fluoride ion releasing analysis was performed with the use of a selective electrode (Combination Fluoride Electrode HI 4110 filled with HI 7075 electrolyte for the reference electrode from Hanna instruments). The electrode was previously calibrated, 
with standardized solutions with concentrations varying between $10^{-5}-10^{-2}$ mol/L F-. All measurements, both for the investigated and the standardized solutions were performed in $50 \mathrm{~mL}$ of distilled water and TISAB III buffer solutions $(45: 5)$ at $37^{\circ} \mathrm{C}( \pm 2)$. Fluoride release was reported in ppm.

\subsubsection{HPLC Determination of Residual Monomers}

Samples Preparation

After 60 days, the storage medium (distilled water/TISAB III) in which the samples were immersed in order to perform the fluoride release assessment, was frozen and then lyophilized in a Model Alpha 1-4 LDPLUS until the liquid was completely removed. The residual monomers from restoration composites were determined from the lyophilized storage medium (water) and the residue was re-suspended in $0.6 \mathrm{~mL}$ of acetonitrile, filtered in $0.22 \mu \mathrm{m}$ PTFE filters and analyzed by HPLC.

\section{Instrumentation and Method}

The analyzes were performed on a Jasco HPLC chromatograph (Jasco International Co., Ltd., Tokyo, Japan) that was equipped with an intelligent pump PU-980, a ternary gradient unit LG-980-02, an intelligent column thermostat CO-2060 Plus, an intelligent detector UV-975, and an injection valve that was equipped with a $20 \mu \mathrm{L}$ sample loop (Rheodyne, Thermo Fischer Scientific, Waltham, MA, USA). The system was controlled and the experimental data analyzed with the ChromPass software (version v1.7, Jasco International Co., Ltd., Tokyo, Japan). Separation was performed on a Lichrosorb RP-C18 column $(25 \times 0.46 \mathrm{~cm})$ at a column temperature of $21^{\circ} \mathrm{C}$. The mobile phase was a mixture of acetonitrile (A, HPLC grade) and water (Milipore ultrapure water) and a gradient was applied according to the following method: $0-15 \mathrm{~min}$, linear gradient $50-80 \% \mathrm{~A}$; 15-25 min, linear gradient $80-50 \%$ A. The flow rate was $0.9 \mathrm{~mL} / \mathrm{min}$ and the injected volume was always $20 \mu \mathrm{L}$. UV detection was performed at $204 \mathrm{~nm}$ to monitor the elution of all analytes (Bis-GMA and TEGDMA) because it shows significant absorption at this wavelength. Stock solutions of Bis-GMA and TEGDMA reference standards $(1 \mathrm{mg} / \mathrm{mL})$ were prepared in acetonitrile and stored at $4{ }^{\circ} \mathrm{C}$. The linearity of the response to the analytes was established with four concentration levels and the regression factors $\mathrm{R} 2$ were higher than 0.998. All of the analyses were perform in triplicates for both the standard and the samples.

The residual monomer amount has been determined from the HPLC chromatograms of the extracts and it was calculated as percentage related to the initial amount of monomer in the sample and the weight of the sample, respectively [26].

\subsubsection{Mechanical Properties and Statistical Analyses}

The samples used for testing the mechanical properties were obtained in teflon molds and light-cured with a LED.E dental lamp (GuilinWoodpecker Medical Instruments Co., Guangxi, China) with a wave length of $470 \mathrm{~nm}$ and intensity of $950 \mathrm{~mW} \mathrm{~cm}$. For each tested material (F00, F02, F03 and the experimental giomer) a number of 10 samples were fabricated.

Before determining mechanical properties, all samples were stored for $24 \mathrm{~h}$ in a thermostatic bath at $37^{\circ} \mathrm{C}$. The containers were left to dry at room temperature and after another $24 \mathrm{~h}$ they were measured with a digital measurer. Mechanical properties were analyzed according to ISO 4049/2000 standard [27]. For measuring mechanical resistance properties, a Universal Testing Machine (LF Plus, LLOYD, Instrument, Ametek Inc., West Sussex, England) and Nexygen software was used.

\section{Compressive Strength}

The samples for determining the compressive strength were of cylindrical shape, $8 \mathrm{~mm}$ high and $4 \mathrm{~mm}$ in diameter. The polymerization of the samples was performed 
in increments of $2 \mathrm{~mm}$ height, for $40 \mathrm{~s}$ each. The pressing speed of the machine was $0.75 \mathrm{~mm} / \mathrm{min}$.

For the calculation of the compressive strength (CS) in MPa, the following formula was applied (1) [27]:

$$
C S=F / \pi r^{2}
$$

where $F$ is the maximum applied strength $(\mathrm{N})$, and $r$ is the sample radius $(\mathrm{mm})$.

The Diametral Tensile Strength (DTS)

For determining tensil strength, the diametral compression test was used. Samples were prepared in the same way as described for the compression strength test, having a cylindrical shape, $3 \mathrm{~mm}$ thick and $6 \mathrm{~mm}$ in diameter. The samples were pressed against the cylindrical generator. The force $(F)$ acting on the cylinder, caught between the plates of the device, determines the appearance of the tensile forces on the vertical diameter plane. The calculation formula for tensile strength (DTS, measured in MPa) was applied as follows (2) [27]:

$$
D T S=2 \times F / \pi \times D \times T
$$

where $F$ is the maximum applied strength $(\mathrm{N})$, and $T$ is the thickness and $D$ the diameter of the sample.

\section{Flexural Strength (FS) and Flexural Modulus}

For determining the flexural strength $(F S)$, rectangular shaped samples were fabricated in a teflon mold, $25 \mathrm{~mm}$ in length, $2 \mathrm{~mm}$ height and $2 \mathrm{~mm}$ width. The light-curing of the samples was performed in 5 distinct areas along the sample, on both sides, for $20 \mathrm{~s}$ on each point. The samples were subjected to a three-point load with length $(\mathrm{l})=20 \mathrm{~mm}$ between the supports. The transverse speed of the test machine was $0.75 \mathrm{~mm} / \mathrm{min}$.

For calculating the flexural strength (FS), the following formula was applied (3) [27]:

$$
F S=3 F I / 2 b h^{2}
$$

where $F$ is the maximum load applied to the specimen $(\mathrm{N}), l$ is the span between the supports $(20 \mathrm{~mm})$, and $b$ and $h$ are the width and height, of the specimen (mm), respectively.

The Young's modulus (YM) for bending determined the slope of the linear part of the force-deflection diagram.

\section{Statistical Analyses}

The data were analyzed with the ANOVA test and Tukey test for post-hoc comparison between sample groups; the significance level $\alpha=0.05$. The statistical analysis was performed with the Origin2019b Graphing\&Analysis software (OriginLab, Northampton, MA, USA).

\section{Results}

\subsection{Fluoride Release}

Figure 1 illustrates total fluoride release distribution over a period of 60 days of investigation.

In Figure 1, total fluoride release/day is presented, with the highest mean value registered for material B-F02. During the first day of investigation, material B-F00 releases a higher cumulated fluoride quantity when compared to the experimental giomer. However, starting with the 2nd day and over the entire period, the lowest mean values of cumulative fluoride release/day were registered by B-F00. 


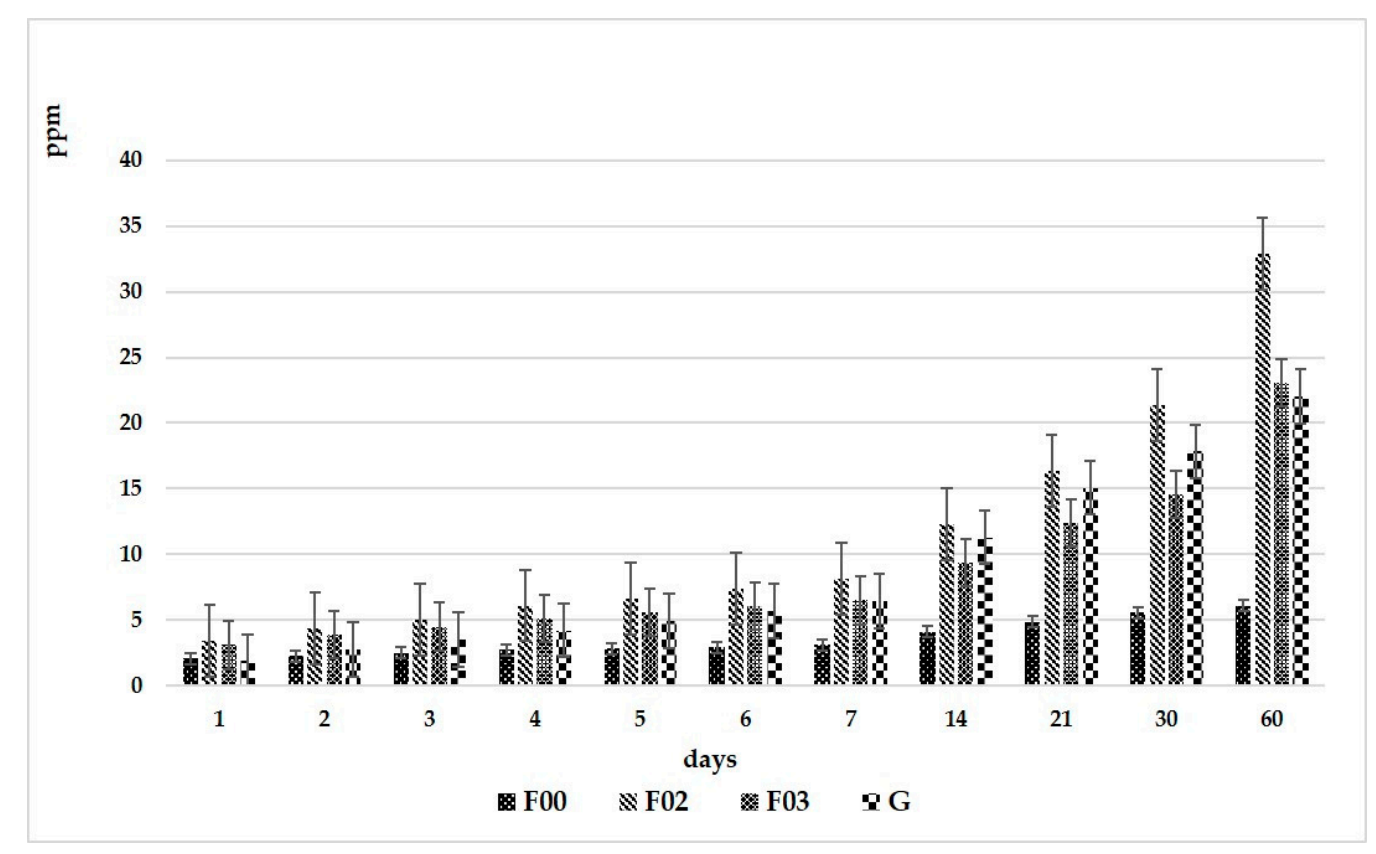

Figure 1. Total fluoride release over the 60 days investigation period.

During the first day, the highest mean values for total fluoride release are registered for B-F03 (3.099 ppm) and B-F02 (3.389 ppm). The mean values of fluoride release in the first day of investigation for the experimental giomer G was 1.871 ppm and for B-F00, 2.064 ppm.

On the 7th day, the highest value of total fluoride released is $8.11 \mathrm{ppm}$ (B-F02) and the lowest is $3.10 \mathrm{ppm}$ (B-F00). The total fluoride released by the experimental giomer, on the 7th day was $6.43 \mathrm{ppm}$, close to $6.50 \mathrm{ppm}$ registered for B-F-03 giomer.

On the 30th day, the highest value of total fluoride released was registered for BF02, 21.39 ppm and the lowest for B-F00 (5.55 ppm). The total fluoride released by the experimental giomer on the 30th day was 17.84 ppm, and for B-F03, 14.54 ppm.

At the end of the investigation period, at 60 days, the mean values of the total amounts of fluoride released were as follows: 32.92 ppm (B-F02), 23.06ppm (B-F03), 22.04 ppm (G) and 6.08 ppm (B-F00).

\subsubsection{Statistical Analyses for Total Fluoride Release over a 60 Day Period:}

Four samples were fabricated for each of the investigated materials and their behavior regarding fluoride release was observed over a 60 days period and it showed statistically significant differences $(p<0.05)$.

For the cumulative fluoride release, the conclusion was that there are statistically significant differences among all analyzed groups $(p<0.05)$ on each day. The Tukey test highlighted the differences between: B-F00 and B-F02 and B-F03 over the entire period, whereas B-F02 and B-F03 presented no statistically significant differences over the first 7 days of investigation, but they became noticeable starting with day 14 . No statistically significant differences were noted between $\mathrm{G}$ and B-F03 over the entire 60 days period, also G-B-F00 had no statistically significant differences over the first 3 days, G and B-F02 had no statistically significant differences in the last 4 days of the investigation, with all other days the differences between G-B-F00 and G-B-F03 being statistically significant.

When analyzing the mean values of fluoride quantity released in the 2nd day, (Figure 2), they are lower than the first day, with the experimental giomer $\mathrm{G}$ releasing 0.908 ppm, similar to F02, 0.936 ppm. B-F03 registered mean values of 0.801 ppm, and B-F00, 0.199 ppm fluoride. 


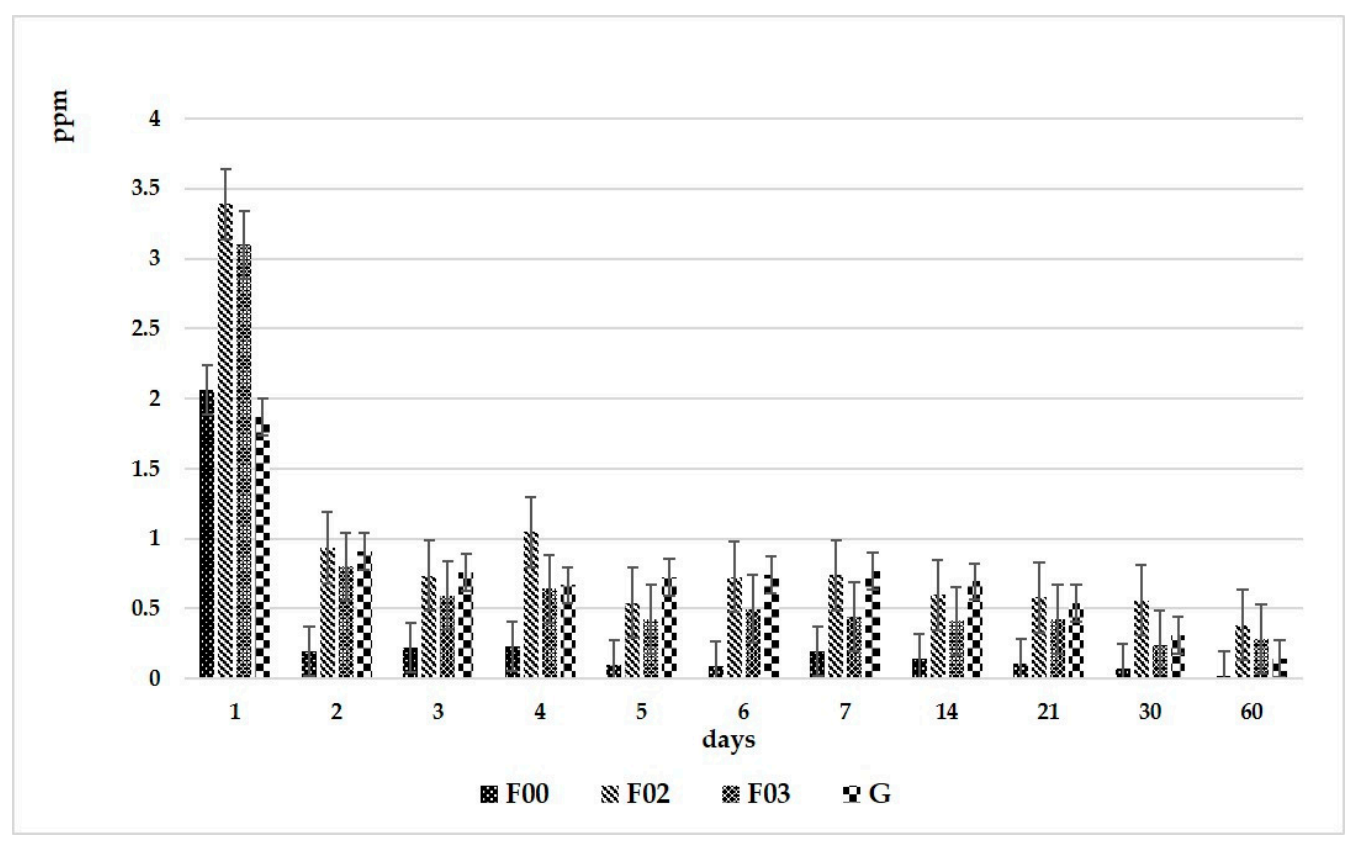

Figure 2. Daily fluoride release for the investigated materials.

Mean values of fluoride release for $\mathrm{G}$ and B-F02 on the 7th day of the investigation are around $0.7 \mathrm{ppm}$; for B-F03, $0.44 \mathrm{ppm}$ and for B-F00, $0.19 \mathrm{ppm}$.

The highest mean value of fluoride release, compared to the other giomers, was registered on the 14th day, for $\mathrm{G}(0.69 \mathrm{ppm})$. The average values of fluoride released by the experimental giomer during the rest of the investigation period were: $0.54 \mathrm{ppm}$ (on the 21 day), $0.30 \mathrm{ppm}$ (on the 30 day) and $0.14 \mathrm{ppm}$ on the 60th day.

Material B-F02 released the highest fluoride mean values during days 21st, 30 and 60 (0.58 ppm, 0.55 ppm, 0.38 ppm respectively). In Figure 2 we can observe that although B-F00 released around $2 \mathrm{ppm}$ fluoride during the first day, in the later days, mean values decreased ( $0.19 \mathrm{ppm}$ on the 2 nd day, $0.19 \mathrm{ppm}$ day 7, $0.07 \mathrm{ppm}$ day 30 and $0.01 \mathrm{ppm}$ the 60th day).

Although the daily amount of fluoride released by the experimental giomer on the first day and at the end of the investigation period approaches the value of the B-F00 giomer, during 21 days of investigation it is quite constant, being closer in value to the of the giomer B-F02.

\subsubsection{Statistical Analyses of Daily Fluoride Release}

For the daily fluoride release there were statistically significant differences found among all analyzed groups $(p<0.05)$ per investigation days. Tuckey showed differences between the B-F00 and B-F03 pair, B-F00 and B-F02 pair during the entire investigation period, wearas the B-F02 and B-F03 pair displayed no statistically significant differences. The experimental giomer $\mathrm{G}$ presented no differences in comparison to B-F02, however, for the most of the investigation period, statistically significant differences were detected for $\mathrm{B}-\mathrm{F} 00$ and B-F02 materials.

\subsection{HPLC Determination of Residual Monomers}

The quantity of residual monomers released by the investigated materials were determined at 30 days, after performing the sorbtion and solubility test [13].

In Table 2 and Figure 3 (chormatograms) the highest percentage of the residual monomers (Bis-GMA and TEGDMA) is shown in the depositing environment of B-F00 $(3 \%)$, wearas the lowest was found for $\mathrm{G}(1.2 \%)$. The commercial giomers released a higher percentage of TEGDMA, the experimental giomer released a higher percentage of Bis-GMA, somewhat similar to B-F03. 
Table 2. The residual monomer $(\% \pm \mathrm{SD})$ related to the weight of the sample.

\begin{tabular}{cccc}
\hline Sample & TEGDMA \% & Bis-GMA \% & Total \% \\
\hline B-F00 & $2.5 \pm 0.83$ & $0.5 \pm 0.09$ & $3 \pm 0.46$ \\
B-F02 & $1.7 \pm 0.76$ & $0.6 \pm 0.10$ & $2.3 \pm 0.43$ \\
B-F03 & $1.1 \pm 0.23$ & $0.9 \pm 0.21$ & $2 \pm 0.22$ \\
G & $0.4 \pm 0.11$ & $0.8 \pm 0.16$ & $1.2 \pm 0.13$ \\
\hline
\end{tabular}
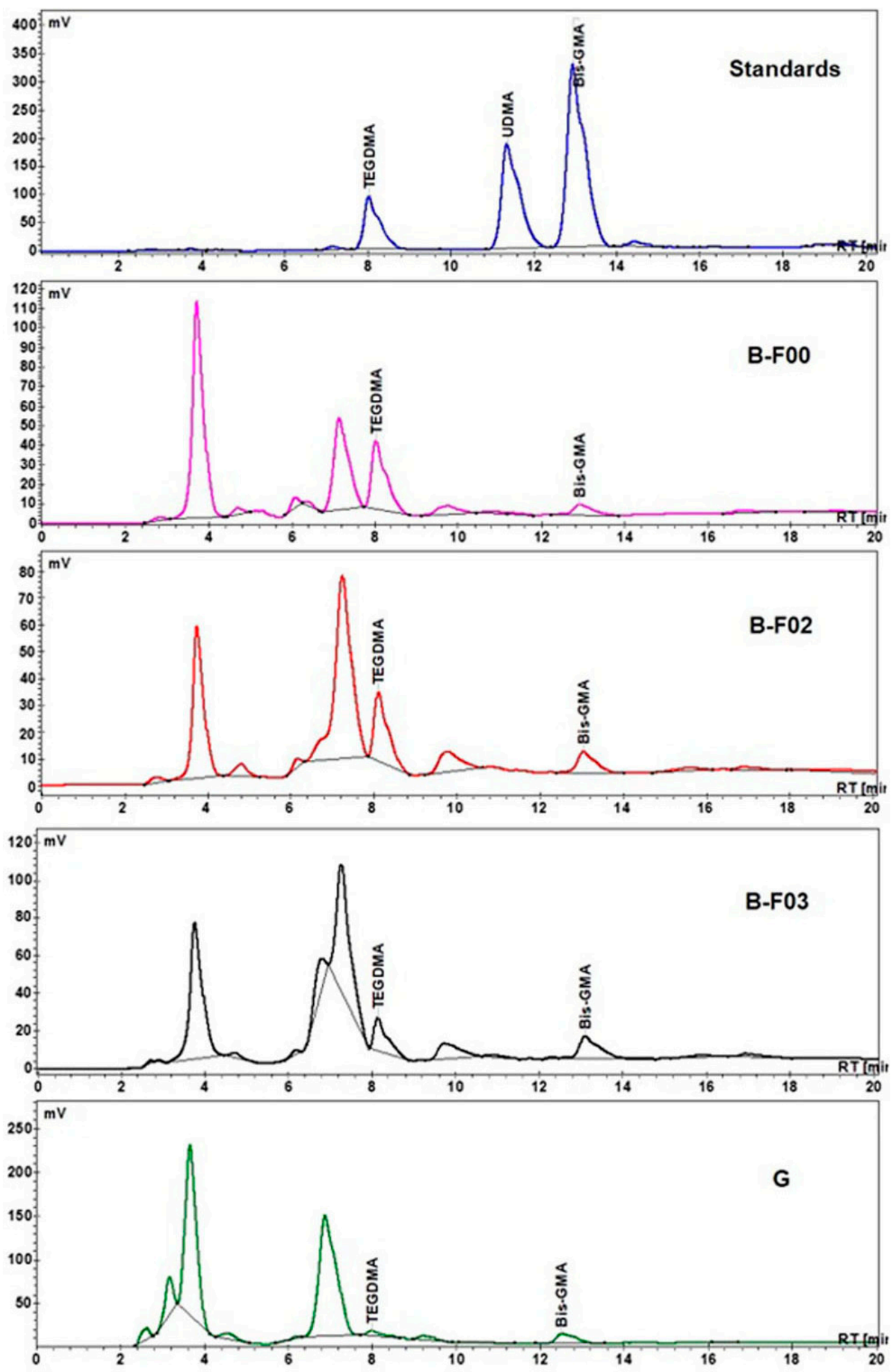

Figure 3. HPLC chromatograms of standards and investigated samples. 


\subsection{Mechanical Properties}

In Figures 4 and 5, the mean values of the mechanical properties of the investigated materials are presented. The highest value for CS is that of material B-F02. The compresion strength of the experimental giomer $\mathrm{G}$, is situated between the values obtained for B-F00 and B-F03. Regarding DTS resistance, B-F00 had the highest value, whilst the highest FS was for material B-F03. The experimental giomer $\mathrm{G}$ has a lower traction resistance and FS compared to the other investigated materials.
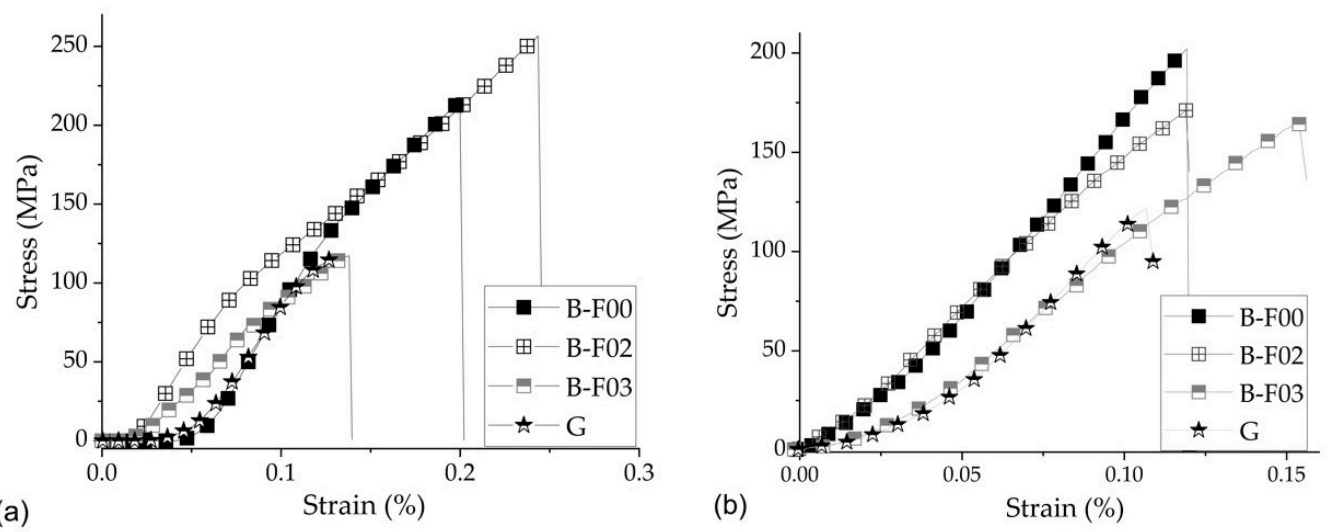

Figure 4. (a) The strain-stress curve of compression test; (b) traction strength test.

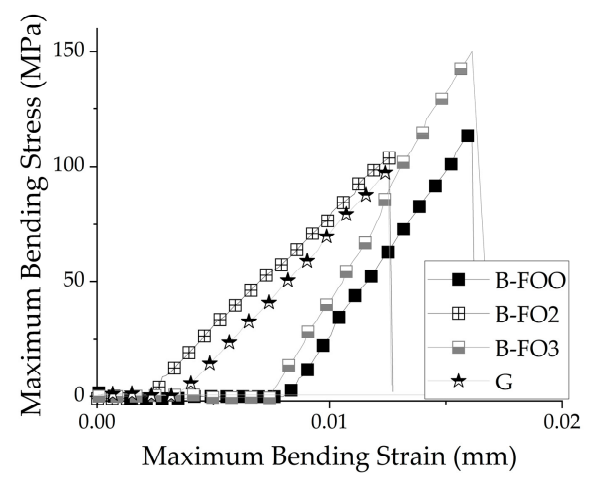

Figure 5. Flexural test.

Regarding the elasticity module, the highest registered value among the investigated samples was obtained for B-F03, and the lowest for the experimental giomer.

The limit imposed in the international standard ISO 4049/2009 for flexural strengths of giomers is $80 \mathrm{MPa}$. All the giomers presented values of flexural strengths higher than this limit [27].

\section{Statistical Analysis}

The study groups are the 4 different biocomposites, the comparison being made between all of them, for each mechanical test, each group being represented by $n=10$ results.

For the compresion strength test, samples showed a high statistically significant difference. The Tukey test for post hoc comparisson found statistically significant differences between all sample groups with the exception of the following pairs: B-F00 and B-F02; B-F03 and G.

For the traction strength test, the sample groups had a low statistical difference $(p=0.04565)$, the Tukey test showed a signifficant difference only between B-F00 and G pair.

For the Diametral Tensile Strength (DTS) performed in 3 distinct points the one-way ANOVA indicates a statistically significant difference $(p$-value $=0.00368)$ between B-F02-BF03 and B-F03-G. 


\section{Discussion}

Fluoride release from dental materials is possible by diffusion of set ions in a wet environment. To this effect it is important to take into account the materials capacity to sustain water diffusion without having an excessively high water sorption [6]. Itota et al. [7] stated that in addition to water sorption, partial removal of polymeric chains from the resin matrix of polymerized composites can also influence fluoride release capacity [9] very important because of its biocompatibility [28].

Fluoride release mostly takes place during the first week, through an acid-base reaction on the surface of the pre-reacted glass particles [9].

In the current study it was determined that the experimental giomer $\mathrm{G}$ released $1.87 \mathrm{ppm}$ of fluoride after the first day, $0.766 \mathrm{ppm}$ after a week and $0.307 \mathrm{ppm}$ fluoride after 30 days. The giomer B-F03 released $3.1 \mathrm{ppm}$ fluoride after the first day, $0.442 \mathrm{ppm}$ after the first week and $0.242 \mathrm{ppm}$ fluoride after 30 days.

Harhash et al. found that the commercial giomer Beautifil Flow Plus F03, A2 color, released $1.0020 \mathrm{ppm}$ of fluoride after the first day, $0.4140 \mathrm{ppm}$ after the first week and after four weeks $0.3165 \mathrm{ppm}$ of fluoride. The differences between materials may be due to the size of the samples, material batches and the sensitivity of the devices used for analyses [9].

High performance liquid chromatography (HPLC) is considered to be the most performant technique for determining the type and quantity of residual monomers released by composite resins. By HPLC technique, the non-polar compounds were eluted from the matrix of the composite resin, separating the components in the order of their hydrophobic properties. Dissolution of the monomers in the mobile phase leads to a more controlled separation [29].

Residual monomers were released from the polymeric matrix through the process of diffusion, depending on their hydrophobicity, molecular weight and flexibility of the polymer. TEGDMA is lighter and has a higher mobility when compared to the more rigid Bis-GMA molecule, and as a consequence was released in a higher amount from the matrix [30]. Depending on the storage solution, hydrophilic structures will be attracted to a watery environment, whereas an organic medium will be more accessible to hydrophobic particles. The diffusion of the storage liquid into the micro-pores of the resin matrix will lead to a progressive expansion of the pores and swelling of the polymeric matrix. The degree of swelling is also influenced by the rigidity and reticulation of the polymeric matrix. It is important that the quantity of residual monomers released to be as low as possible, ensuring a complete polymerization of the material. Ferracane and Condon stated that $85-100 \%$ percent of the residual monomer is released during the first $24 \mathrm{~h} \mathrm{[31].} \mathrm{Other}$ literature data suggests also that a higher quantity of TEGDMA is eluted during the first $24 \mathrm{~h}$ after setting, and a lower quantity after one month [31].

In their study, Ilie et al. reported that Beautifil Bulk restorative giomer has a flexural strength of $106.0 \pm 12.7 \mathrm{MPa}$, the quantity of the inorganic filler (87 filler $\mathrm{wt} \%$ ) being reflected in the mechanical properties. ISO standard 4049 does not specify an inferior limit for the elasticity module that is in direct relation to the restoration material deformation when under the action of masticatory forces [32].

The current study found that giomer B-F00 (67.3 filler $\mathrm{wt} \%$ ) has a flexural strength of $114.83 \pm 15.45 \mathrm{MPa}$, even though the filler quantity is lower than that of a bulk fill giomer [10]. Also, the study of Colceriu-Burtea et al. [26], found that Beautifil II has a flexural strength of $115.7 \mathrm{MPa}$ and the experimental giomers, 89.2-108.8 $\mathrm{MPa}$. The experimental giomer ( 60 filler $\mathrm{wt} \%$ ), that has Bis-GMA and TEGDMA in the resin matrix, registered a value of $98.822 \pm 13.02 \mathrm{MPa}$ for the flexural strength.

Imai and al. [5] stated that the resin matrix composition has the main influence upon the flexural strength of flowable composites and an explanation based solely on the filler percentage is insufficient. They reported a value of $116.2 \mathrm{MPa}$ for the flexural strength of B-F00. The consistency of the monomer mixture, the type of filler, size and particle distribution can influence the mechanical properties of materials. Shouha found a 126.3 MPa value for the flexural strength of giomer B-F03 [33]. 
Regarding the compression strength, the highest value was identified for B-F02 with $255.95 \pm 28.19 \mathrm{MPa}$. Other sources stated that B-F00 and B-F03 have compression strength of $358 \mathrm{MPa}$ and flexural strength of $120 \mathrm{MPa}$ and conventional giomers (Beautifill II) compression strength of $271,356 \pm 19,653 \mathrm{MPa}[34,35]$.

All the giomers investigated in this study differ from each other but not to a large extent and the results obtained are comparable to those in the literature. The limitations of the present study consist in the fact that there are a only few reports in the literature on flowable giomers and the results of the investigations may differ, depending on the method or equipment used

In the future, it would be interesting to investigate other properties of giomers, glass ionomers and dental composites; perhaps an important aspect would be how these materials could help in the process of dental remineralization [36,37].

\section{Conclusions}

The daily amount of fluoride released by the experimental giomer is close to the values reported for Beautifil giomers, making them similarly effective regarding the caries prevention and remineralization aspects. On the first day, in descending order of the fluoride amount released we obtained the following: B-F02 $>$ B-F03 $>$ B-F00 $>$ G and at the end of the investigation period, at 60 days: B-F02 $>$ B-F03 $>$ G $>$ B-F00. The highest mean value for total fluoride release/day is registered for material B-F02.

The Beautifil giomers released a higher percentage of TEGDMA, the experimental giomer released a higher percentage of Bis-GMA, somewhat similar to B-F03. Residual monomers are somewhat inevitable, given the constant interaction direct restoration materials have with water.

All the giomers presented values of flexural strengths higher than the limit imposed by the standard, so all tested materials, including the experimental giomer have adequate mechanical properties.

Further investigations, for example fluoride recharge through topical applications and re-release into the environment, are still needed to reach optimal qualities of the experimental giomer, making it suitable for dental applications.

Author Contributions: Conceptualization, D.P. and C.P.; validation, D.D.; investigation, S.C. and M.F.; writing-original draft preparation, M.E.R.; supervision, M.M. All authors have read and agreed to the published version of the manuscript.

Funding: This research received no external funding.

Institutional Review Board Statement: Not applicable.

Informed Consent Statement: Not applicable.

Data Availability Statement: The data presented in this study are available on request from the corresponding author.

Acknowledgments: This work was sustained by: Iuliu Hatieganu University of Medicine and Pharmacy, Cluj-Napoca, by the internal Project: Nr. 1680/75, of 19 January 2018; the Romanian Ministry of Education and Research, Project nr. 334PED/2020. The authors thank Nils Becker, ISM-Industrial Specialty Materials, Ferro GmbH, Frankfurt, Germany for providing the IS 501102 Dentalglass 0.70 sample.

Conflicts of Interest: The authors declare no conflict of interest.

\section{References}

1. Lee, I.B.; Cho, B.H.; Son, H.H.; Um, C.M. Rheological characterization of composites using a vertical oscillation rheometer. Dent. Mater. 2006, 23, 425-432. [CrossRef]

2. Wood, I.; Jawad, Z.; Paisley, C.; Brunton, P. Non-carious cervical tooth surface loss: A literature review. J. Dent. 2008, 36, 759-766. [CrossRef]

3. Lazaridou, D.; Belli, R.; Petschelt, A.; Lohbauer, U. Are resin composites suitable replacements for amalgam? A study of two-body wear. Clin. Oral Investig. 2015, 19, 1485-1492. [CrossRef] [PubMed] 
4. Sumino, N.; Tsubota, K.; Takamizawa, T.; Shiratsuchi, K.; Miyazaki, M.; Latta, M.A. Comparison of the wear and flexural characteristics of flowable resin composites for posterior lesions. Act. Odontol. Scand. 2013, 71, 820-827. [CrossRef]

5. Imai, A.; Takamizawa, T.; Sugimura, R.; Tsujimoto, A.; Ishii, R.; Kawazu, M.; Saito, T.; Miyazaki, M. Interrelation among the handling, mechanical, and wear properties of the newly developed flowable resin composites. J. Mech. Behav. Biomed. Mater. 2019, 89, 72-80. [CrossRef]

6. Najma Hajira, N.S.W.; Meena, N. GIOMER-The Intelligent Particle (New Generation Glass Ionomer Cement). Int. J. Dent. Oral Health. 2015, 2, 1-5. [CrossRef]

7. Itota, T.; Carrick, T.E.; Yoshiyama, M.; McCabe, J.P. Fluoride release and recharge in giomer, compomer and resin composite. Dent. Mater. 2004, 20, 789-795. [CrossRef]

8. Okuyama, K.; Murata, Y.; Pereira, P.N.; Miguez, P.A.; Komatsu, H.; Sano, H. Fluoride release and uptake by various dental materials after fuoride application. Am. J. Dent. 2006, 19, 123-127. [CrossRef] [PubMed]

9. Harhash, A.Y.; ElSayad, I.I.; Zaghloul, A.G. A comparative in vitro study on fluoride release and water sorption of different flowable esthetic restorative materials. Eur. J. Dent. 2017, 11, 174. [CrossRef]

10. Abdel-Karim, U.M.; El-Eraky, M.; Etman, W.M. Three-year clinical evaluation of two nano-hybrid giomer restorative composites. Tanta Dent. J. 2014, 11, 213-222. [CrossRef]

11. Gonulol, N.; Ozer, S.; Sen Tunc, E. Water sorption, solubility, and color stability of giomer restoratives. J. Esthet. Restor. Dent. 2015, 27, 300-306. [CrossRef]

12. Rusnac, M.E.; Gasparik, C.; Delean, A.G.; Aghiorghiesei, A.I.; Dudea, D. Optical properties and masking capacity of flowable giomers. Med. Pharm. Rep. 2021, 94, 99-105. [CrossRef]

13. Rusnac, M.E.; Prodan, D.; Cuc, S.; Petean, I.; Prejmerean, C.; Gasparik, C.; Dudea, D.; Moldovan, M. Water Sorption and Solubility of Flowable Giomers. Material 2021, 14, 2399. [CrossRef]

14. Prejmerean, C.; Moldovan, M.; Silaghi-Dumitrescu, L.; Prodan, D.; Furtos, G.; Trif, M.; Popescu, V.; Pascalau, V.; Petrea, C.M.; Silaghi-Dumitrescu, R. Composition versus physico-mechanical properties of some dental experimental polymers. Mater. Plast 2011, 48, 27-32. [CrossRef]

15. Hadi, M.R. Effect of Increased Fluoride Contents on Fluoride Release from Glass Ionomer Cements. Sys. Rev. Pharm. 2020, 11, 440-443. [CrossRef]

16. Cury, J.A.; de Oliveira, B.H.; Dos Santos, A.P.; Tenuta, L.M. Are fluoride releasing dental materials clinically effective on caries control? Dent. Mater. 2016, 32, 323-333. [CrossRef] [PubMed]

17. Tarasingh, P.; Reddy, J.S.; Suhasini, K.; Hemachandrika, I. Comparative Evaluation of Antimicrobial Efficacy of Resin-Modified Glass Ionomers, Compomers and Giomers-An Invitro Study. JCDR 2015, 9, 85-87. [CrossRef] [PubMed]

18. Sauro, S.; Makeeva, I.; Faus-Matoses, V.; Foschi, F.; Giovarruscio, M.; Maciel Pires, P.; Martins Moura, M.E.; Almeida Neves, A.; Faus-Llácer, V. Effects of ions-releasing restorative materials on the dentine bonding longevity of modern universal adhesives after load-cycle and prolonged artificial saliva aging. Materials 2019, 12, 722. [CrossRef] [PubMed]

19. Abdallah, A.M.; Elshehawy, T.M.; Ibrahim, H.M. Fluoride Release and Recharge Behavior of Bioactive Glass Ionomer Cements using Ion Chromatography. Egypt Dent. J. 2019, 65, 399-406. [CrossRef]

20. Choudhary, H.V.; Priyadarshni, P.; Suryavanshi, R.; Rathore, M.; Singh, N. Comparison of Two Resins with Fluoride Release and Uptake Property of Giomer and Polyacid Modified Composite-An In Vitro Assessment. JAMDSR 2019, 7, 188-192. [CrossRef]

21. Tay, F.R.; Pashley, E.L.; Huang, C.; Sano, H.; Hashimoto, M. The glass-ionomer phase in resin-based restorative materials. J. Dent. Res. 2001, 80, 1808-1812. [CrossRef]

22. Xu, H.H.; Eichmiller, F.C.; Antonucci, J.M.; Yves, L.K. Dental resin composites containing ceramic whiskers and pre-cured glass ionomer particles. Dent. Mater. 2000, 16, 356-363. [CrossRef]

23. Elshweekh, R.A.; Bakry, N.S.; Talaat, D.M.; Ahmed, D.M. Fluoride release and rerelease after recharging of two hybrid resin restorations in primary teeth, "a comparative in vitro study". Alex. Dent. J. 2019, 44, 114-119. [CrossRef]

24. Bănuț Oneț, D.; Barbu Tudoran, L.; Delean, A.; Șurlin, P.; Ciurea, A.; Roman, A.; Bolboacă, S.; Gasparik, C.; Muntean, A.; Soancă, A. Adhesion of Flowable Resin Composites in Simulated Wedge-Shaped Cervical Lesions: An In Vitro Pilot Study. Appl. Sci. 2021, 11, 3173. [CrossRef]

25. Prejmerean, C.; Prodan, D.; Vlassa, M.; Streza, M.; Buruiana, T.; Colceriu, L.; Prejmerean, V.; Cuc, S.; Moldovan, M. ATR technique, an appropriate method for determining the degree of conversion in dental giomers. Meas. Sci. Technol. 2016, 27, 124008. [CrossRef]

26. Colceriu Burtea, L.; Prejmerean, C.; Prodan, D.; Baldea, I.; Vlassa, M.; Filip, M.; Moldovan, M.; Antoniac, A.; Prejmerean, V.; Ambrosie, I. New pre-reacted glass containing dental composites (giomers) with improved fluoride release and biocompatibility. Materials 2019, 23, 4021. [CrossRef]

27. ISO-4049. Dentistry—Polymer-Based Restorative Materials; International Organization for Standardization: London, UK, 2019. Available online: https:/ / www.iso.org/standard/42898.html (accessed on 18 April 2021).

28. Iviglia, G.; Kargozar, S.; Baino, F. Biomaterials, Current Strategies, and Novel Nano-Technological Approaches for Periodontal Regeneration. J. Func. Biomater. 2019, 10, 3. [CrossRef]

29. Cebe, M.A.; Cebe, F.; Cengiz, M.F.; Cetin, A.R.; Arpag, O.F.; Ozturk, B. Elution of monomer from different bulk-fill dental composite resins. Dent. Mater. 2015, 31, 141-149. [CrossRef]

30. Ferracane, J.L. Resin composite-State of the art. Dent. Mater. 2011, 27, 29-38. [CrossRef] 
31. Gul, P.; Alp, H.H.; Özcan, M. Monomer release from bulk-fill composite resins in different curing protocols. J. Oral Sci. 2020, 62, 288-292. [CrossRef]

32. Ilie, N. High viscosity bulk-fill giomer and ormocer-based resin composites: An in-vitro comparison of their mechanical behaviour. Stoma Edu J. 2016, 3, 54-62. [CrossRef]

33. Shouha, P.; Swain, M.; Ellakwa, A. The effect of fiber aspect ratio and volume loading on the flexural properties of flowable dental composite. Dent. Mater. 2014, 30, 1234-1244. [CrossRef] [PubMed]

34. Giomer Technology. Taking Dentistry to the Next Level. Bioactive Dental Materials. Available online: https://www.shofu.com/ wp-content/uploads/Giomer-BRO-US.pdf (accessed on 18 April 2021).

35. Quader, S.A.; Alam, M.S.; Bashar, A.K.; Gafur, A.; Al Mansur, M.A. Compressive strength, fluoride release and recharge of giomer. Update Dent. Coll. J. 2012, 2, 28-37. [CrossRef]

36. Muşat, V.; Anghel, E.M.; Zaharia, A.; Atkinson, I.; Mocioiu, O.C.; Buşilă, M.; Alexandru, P. A Chitosan-Agarose PolysaccharideBased Hydrogel for Biomimetic Remineralization of Dental Enamel. Biomolecules 2021, 11, 1137. [CrossRef] [PubMed]

37. Butera, A.; Pascadopoli, M.; Gallo, S.; Lelli, M.; Tarterini, F.; Giglia, F.; Scribante, A. SEM/EDS Evaluation of the Mineral Deposition on a Polymeric Composite Resin of a Toothpaste Containing Biomimetic Zn-Carbonate Hydroxyapatite (microRepair ${ }^{\circledR}$ ) in Oral Environment: A Randomized Clinical Trial. Polymers 2021, 13, 2740. [CrossRef] [PubMed] 